\title{
Diarrhea Prevalence and Sociodemographic Factors among Under-Five Children in Rural Areas of North Gondar Zone, Northwest Ethiopia
}

\author{
Atalay Getachew, ${ }^{1}$ Tadesse Guadu, ${ }^{1}$ Alebachew Tadie, ${ }^{2}$ Zemichael Gizaw, ${ }^{1}$ \\ Mulat Gebrehiwot, ${ }^{1}$ Daniel Haile Cherkos ${ }^{D}$, ${ }^{1}$ Martha Alemayehu Menberu ${ }^{D},^{3}$ \\ and Teklay Gebrecherkos ${ }^{3}{ }^{3}$ \\ ${ }^{1}$ University of Gondar, College of Medicine and Health Sciences, Institute of Public Health, \\ Department of Environmental \& Occupational Health \& Safety, P.O. Box 196, Gondar, Ethiopia \\ ${ }^{2}$ University of Gondar, College of Natural and Computational Sciences, Department of Biology, P.O. Box 196, Gondar, Ethiopia \\ ${ }^{3}$ University of Gondar, College of Medicine and Health Sciences, School of Biomedical and Laboratory Sciences, \\ Department of Medical Microbiology, P.O. Box 196, Gondar, Ethiopia
}

Correspondence should be addressed to Teklay Gebrecherkos; estiftg17@gmail.com

Received 1 January 2018; Revised 12 April 2018; Accepted 19 April 2018; Published 3 June 2018

Academic Editor: Lavjay Butani

Copyright (C) 2018 Atalay Getachew et al. This is an open access article distributed under the Creative Commons Attribution License, which permits unrestricted use, distribution, and reproduction in any medium, provided the original work is properly cited.

\begin{abstract}
Background. Diarrheal disease remains one of the principal causes of morbidity and mortality in infants and children in developing countries, including Ethiopia. Risk factors for diarrhea vary by settings and have important implications for developing intervention strategies to reduce the burden of the disease. Thus, the aim of this study was to assess diarrhea prevalence and sociodemographic factors among under-five children in rural areas of North Gondar Zone. Methods. A community-based cross-sectional study was conducted from April to June 2016 among 736 randomly selected households with one child under five years old. A structured questionnaire was used for collecting information on sociodemographic characteristics and diarrheal occurrence. Data was analyzed using SPSS version 20. The bivariate and multivariable logistic regression analysis were used to determine the association between risk factors and diarrheal occurrence, and a p value $<0.05$ was taken as statistically significant. Results. A total of 736 under-five children and their respondents were enrolled during the study period. Almost all respondents were biological mothers $96.4 \%$ (709/736), married 94.2\% (693/736), and house wives $86 \%(632 / 736)$. The overall prevalence of diarrheal disease among under-five children was $22.1 \%$ (163/743). Of these, children with age group of less than one year old, $7.7 \%$ (57/736), were commonly infected with diarrheal diseases. Children less than or equal to one year $[\mathrm{AOR}=1.82,95 \% \mathrm{CI}=(1.39,4.63)]$, guardians $[\mathrm{AOR}=4.37$, $95 \% \mathrm{CI}=(1.73,11.1)]$, and children with no breast feeding practice $[\mathrm{AOR}=3.13,95 \% \mathrm{CI}=(1.62,6.03)]$ were the major risk factors for the occurrence of diarrhea. Conclusion. Childhood diarrhea remains an important health concern in the study area. Occurrence of diarrhea was statistically associated with child age less than or equal to one year, educational status of mother/guardians, and breast feeding. To minimize the magnitude childhood diarrhea, various designing and implementing strategies, such as health education, child care, breast feeding, and weaning practice, integrated with the existing national health extension are quite essential.
\end{abstract}

\section{Introduction}

Diarrhea is one of the waterborne diseases which are reported as the leading cause of death in infants and children [1]. According to WHO, diarrhea is the passage of 3 or more times loose or liquid stools per day or more frequently than the normal for the individual. Globally, diarrheal disease remains one of the principal causes of morbidity and mortality in children. In the globe, under-five children experience on an average 3.2 episodes of diarrhea every year [2] and consequently 1.87 million children will die from dehydration associated with diarrheal disease [3].

In the developing countries, diarrheal disease among under-five children accounts for about $21 \%$ of all deaths $[4,5]$. 
Of this, it is estimated that $15-20 \%$ or more percentage of community diarrheal disease is caused by unsafe drinking water [6]. Ethiopian child mortality rate in 2007 was 199 per 1,000 births, and approximately one of every five deaths every year is due to diarrheal disease [3]. Diarrhea is one of the waterborne diseases which is reported as the leading cause of death in under-five children [7]. Very unfortunately, 46\% of under-five child mortality is due to diarrhea in which water related diseases take the higher percentage.

There are different factors associated with occurrence of diarrhea among children less than five years and these differ from place to place. A study carried out in Kenya showed that six factors were independently associated with diarrheal diseases, occupation of the parent/guardian, care taker not washing hands after changing napkins, child drinking untreated water from the river, child not exclusively breastfed, child not washing hands before eating and after visiting toilet [8].

In Ethiopia, several interventions are going on to reduce morbidity and mortality of children; consistent water source protection is the first line of defense against diarrheal diseases and it is the best method of ensuring safe drinking water [9]. In addition, household level water quality interventions can significantly reduce diarrheal diseases that are caused by pathogens [10]. To do so, regular and frequent assessment of the bacteriological quality of water is needed to get information about diarrheal diseases so as to apply sustainable monitoring system to control the water quality status of municipal and rural water distribution systems [11].

However, in North Gondar Zone, no study is available on the prevalence of diarrhea in under-five children. Therefore, this study aims to assess the prevalence of diarrheal disease and associated sociodemographic factors among under-five children in North Gondar Zone rural areas and intervene improvement strategies based on the assessment result.

\section{Materials and Methods}

2.1. Study Area. This study was conducted in North Gondar Zone from April to June 2016. Gondar is located $739 \mathrm{~km}$ far from Addis Ababa to the northwest of Ethiopia. North Gondar is one of the eleven zones in Amhara Regional State. It has 22 administrative woredas (districts). As per the data gained from North Gondar Zonal Health Department, the total projected population in $2015 / 16$ was $3,704,740$. The majority of which, $2920007(78.8 \%)$, reside in rural areas whereas the rest, $784733(21.2 \%)$, were in urban areas. Moreover, 499542 (13.5\%) of the population were under-five children. According to the reports of the North Gondar Zonal Health Department (2014/15), diarrheal diseases are one of the top ten diseases in the North Gondar Zone.

2.2. Study Design and Period. A community-based crosssectional study design was employed to collect data from households to assess diarrhea prevalence and associated factors from April to June 2016.

2.3. Source Population. All households were in North Gondar Zone with mothers/guardians having under-five children during the study period.
2.4. Study Population. All households were in North Gondar Zone with mothers/guardians having under-five children with diarrhea.

2.5. Inclusion Criteria. All mothers/guardians who have under-five children with diarrhea at selected households were included in the study.

2.6. Exclusion Criteria. (i) Children who were chronically ill and with persistent diarrhea for greater than two weeks were excluded.

(ii) Critically ill or suffering mothers or guardians of the index child were excluded, since it is unethical to take routine information from a suffering person or difficult to obtain complete information.

\subsection{Variables of the Study}

2.7.1. Dependent Variable. The dependent variable is diarrheal disease prevalence.

2.7.2. Independent Variables. The independent variables are sociodemographic characteristics (age, sex, address, educational status, occupation, family members), household size, parental education, maternal occupation, family size, maternal age, number of children under-five years of age, child's age, vaccination status, and breast feeding practice.

\subsection{Sample Size and Sampling Procedure}

2.8.1. Magnitude of Diarrhea. Diarrhea is the passage of 3 or more times loose or liquid stools per day or more frequently than the normal for the individual [2]. The sample size was determined by using the single population proportion formula based on an assumption that $18 \%$ of the underfive children had two-week prevalence of diarrhea in North Gondar [12], with marginal error of $4 \%$, a standard score corresponding to $95 \%$ certainty, design effect of 2 , accounting for two-stage sampling and nonresponse rate $5 \%$. The total sample size included in the study was 743 households that had at least one under-five child. Four districts (Dembia, Gondar Zuria, Chilga, and Sanja) were randomly selected among the 22 total districts of North Gondar Zone, and multistaged sampling procedure was employed.

Using probability proportional (PPS) to size, the number of households was determined in each district. Then, $25 \%$ of total kebeles were selected from each district by simple random sampling technique, and systematic sampling technique was applied to select study households. In case there are more than one under-five child in the same household, index child was selected by lottery method to collect information on child's health characteristics. The first household interview was identified by a modified random walk method, and if there is no mother/guardians or under-five child in the selected household, the next nearest household was included in the survey. 
TABLE 1: Sociodemographic characteristics of respondents among under-five children in rural areas of North Gondar Zone, Northwest Ethiopia, 2016.

\begin{tabular}{|c|c|c|c|}
\hline \multirow[t]{2}{*}{ Variables } & \multicolumn{3}{|c|}{ Diarrhea $(N=736)$} \\
\hline & Yes $(\%)$ & No $(\%)$ & $P$ value \\
\hline \multicolumn{4}{|l|}{ Age group of index child } \\
\hline 0-1 year & $57(7.7)$ & $134(18.2)$ & \multirow{5}{*}{$0.001 *$} \\
\hline $1-2$ years & $47(6.4)$ & $127(17.3)$ & \\
\hline $2-3$ years & $38(5.2)$ & $138(18.8)$ & \\
\hline $3-4$ years & $15(2.0)$ & $119(16.2)$ & \\
\hline $4-5$ years & $06(0.8)$ & $55(7.5)$ & \\
\hline \multicolumn{4}{|l|}{ Sex of index child } \\
\hline Male & $91(12.4)$ & $319(43.3)$ & \multirow[t]{2}{*}{0.97} \\
\hline Female & $72(9.8)$ & $254(34.5)$ & \\
\hline \multicolumn{4}{|c|}{ District hygiene and sanitary condition } \\
\hline Dembia & $64(8.7)$ & $96(13.0)$ & \multirow{5}{*}{$0.001 *$} \\
\hline & & & \\
\hline Gondar Zuria & $36(4.8)$ & $175(23.8)$ & \\
\hline Chilga & $22(3.0)$ & $158(21.5)$ & \\
\hline Sanja & $41(5.6)$ & $144(19.6)$ & \\
\hline \multicolumn{4}{|c|}{ Relation of the respondent to the child } \\
\hline Mother & $155(21.1)$ & $554(75.3)$ & \multirow{3}{*}{0.25} \\
\hline Father & $05(0.6)$ & $16(2.2)$ & \\
\hline Caretaker & $03(0.4)$ & $03(0.4)$ & \\
\hline \multicolumn{4}{|c|}{ Age group of mother/caretaker } \\
\hline $15-24$ years & $36(4.9)$ & $115(15.6)$ & \multirow[t]{3}{*}{0.55} \\
\hline $25-34$ years & $90(12.2)$ & $272(37.0)$ & \\
\hline$>35$ years & $37(5.0)$ & $186(25.3)$ & \\
\hline \multicolumn{4}{|c|}{ Marital status of mother/ guardian } \\
\hline Married & $150(20.4)$ & $543(73.8)$ & \multirow[t]{4}{*}{$0.045 *$} \\
\hline Divorced & $10(1.4)$ & $25(3.4)$ & \\
\hline Single & $02(0.2)$ & $0(0)$ & \\
\hline Widowed & $01(0.1)$ & $05(0.7)$ & \\
\hline \multicolumn{4}{|l|}{ Religion of parents } \\
\hline Orthodox & $159(21.6)$ & $531(72.2)$ & \multirow[t]{3}{*}{0.067} \\
\hline Protestant & $01(0.1)$ & $05(0.7)$ & \\
\hline Muslim & $03(0.4)$ & $37(5)$ & \\
\hline \multicolumn{4}{|c|}{ Educational status of mother/guardian } \\
\hline Illiterate & 85 (11.6) & $346(47)$ & \multirow{6}{*}{$0.001 *$} \\
\hline & & & \\
\hline Read and write & $18(2.5)$ & $44(6.0)$ & \\
\hline Grade $1-8$ & $34(4.6)$ & $101(13.7)$ & \\
\hline Grade $9-12$ & $10(1.4)$ & $65(8.8)$ & \\
\hline Greater than grade 12 & $16(2.2)$ & $17(2.3)$ & \\
\hline \multicolumn{4}{|l|}{ Occupation of mother } \\
\hline Housewife & $138(18.8)$ & $494(67.1)$ & \multirow{2}{*}{$0.001 *$} \\
\hline Government employee & $12(1.6)$ & $12(1.60$ & \\
\hline
\end{tabular}


TABle 1: Continued.

\begin{tabular}{|c|c|c|c|}
\hline \multirow[t]{2}{*}{ Variables } & \multicolumn{3}{|c|}{ Diarrhea $(N=736)$} \\
\hline & Yes $(\%)$ & No (\%) & $P$ value \\
\hline Others (farmer, merchant, etc.) & $13(1.8)$ & $67(9.1)$ & \\
\hline \multicolumn{4}{|l|}{ Age of father } \\
\hline $15-24$ years & $03(0.4)$ & $12(1.6)$ & \multirow[t]{3}{*}{$0.034 *$} \\
\hline $25-34$ years & $79(10.7)$ & $213(28.9)$ & \\
\hline$>35$ years & $81(11.0)$ & $348(47.3)$ & \\
\hline \multicolumn{4}{|l|}{ Educational status of father } \\
\hline Illiterate & $63(8.8)$ & $291(40.5)$ & \multirow{6}{*}{$0.002 *$} \\
\hline & & & \\
\hline Read and write & $33(4.6)$ & $89(12.4)$ & \\
\hline Grade 1-8 & $32(4.5)$ & $105(14.6)$ & \\
\hline Grade 9-12 & $20(2.8)$ & $71(9.9)$ & \\
\hline Greater than grade 12 & $08(1.1)$ & $07(1.0)$ & \\
\hline \multicolumn{4}{|l|}{ Occupation of father } \\
\hline Farmer & $121(16.8)$ & $444(61.8)$ & \multirow[t]{3}{*}{0.36} \\
\hline Government employee & $13(1.8)$ & $50(7.0)$ & \\
\hline Others (farmer, daily labor, etc.) & $22(3.10)$ & $67(9.4)$ & \\
\hline \multicolumn{4}{|l|}{ Family size } \\
\hline$\leq 5$ & $105(14.3)$ & $358(48.6)$ & \multirow[t]{2}{*}{0.65} \\
\hline$>5$ & $58(7.9)$ & $215(29.2)$ & \\
\hline \multicolumn{4}{|l|}{ Average monthly income /ETB/ } \\
\hline$\leq 500$ & $22(3.0)$ & $95(12.9)$ & \multirow[t]{3}{*}{0.75} \\
\hline $501-1000$ & $74(10.1)$ & $232(31.5)$ & \\
\hline$>1000$ & $67(9.1)$ & $246(33.4)$ & \\
\hline \multicolumn{4}{|l|}{ Birth order } \\
\hline $1^{\text {st }}$ & $47(6.4)$ & $214(29.1)$ & \multirow{5}{*}{0.66} \\
\hline & & & \\
\hline $2^{\text {nd }}$ & $41(5.6)$ & $93(12.6)$ & \\
\hline $3^{\text {rd }}$ & $26(3.5)$ & $98(13.3)$ & \\
\hline $4^{\text {th }}$ and above & $49(6.7)$ & $168(22.8)$ & \\
\hline \multicolumn{4}{|l|}{ Current breastfeeding status } \\
\hline Exclusive breastfeeding & $18(2.5)$ & $56(7.6)$ & \multirow[t]{3}{*}{$0.001 *$} \\
\hline Partial breastfeeding & $114(15.5)$ & $255(34.6)$ & \\
\hline Not breastfeeding & $31(4.2)$ & $262(35.6)$ & \\
\hline \multicolumn{4}{|l|}{ Duration of breastfeeding } \\
\hline$\leq 1$ year & $59(8.0)$ & $141(19.2)$ & \multirow[t]{3}{*}{0.34} \\
\hline $1-2$ years & $64(8.7)$ & $251(34.1)$ & \\
\hline$>2$ years & $40(5.4)$ & $181(24.6)$ & \\
\hline \multicolumn{4}{|c|}{ Beginning age of supplementary feeding } \\
\hline$<6$ months & $11(1.5)$ & $25(3.4)$ & \multirow[t]{3}{*}{0.67} \\
\hline 6-12 months & $134(18.2)$ & $481(65.4)$ & \\
\hline$>12$ months & $01(0.1)$ & $17(2.3)$ & \\
\hline
\end{tabular}


TABLE 1: Continued.

\begin{tabular}{lccc}
\hline Measles vaccination status & & & \\
Yes & $120(16.3)$ & $470(63.9)$ & $0.018 *$ \\
No & $43(5.8)$ & $103(14.0)$ & P value \\
\hline Variables & Yes (\%) & No (\%) & 0.30 \\
\hline Rota virus vaccination status & & & \\
Yes & $109(14.8)$ & $358(48.6)$ & $215(29.2)$ \\
\hline No & $54(7.3)$ & & \\
\hline
\end{tabular}

ETB: Ethiopian birr, $\mathrm{N}$ : number, $* \mathrm{P}$ value less than 0.05 .

2.8.2. Data Collection Tool and Method. The data collection tool was structured interview questionnaire to be filled by data collector among randomly selected household to estimate the magnitude of diarrhea in under-five children.

2.8.3. Data Management and Quality Control. The questionnaire was prepared originally in English and translated into Amharic and back to English to keep the consistency of the questions by independent individuals. Training of the data collection team was made to insure the possible quality data. The principal investigator and supervisors checked and reviewed the filled questionnaires to ensure completeness and consistency of the information collected. Incorrectly filled or missed questionnaires were turned back to the data collector for correction in the next day.

2.9. Data Management and Analysis. All collected data was checked for completeness and reliability before entry into software. Data entry and cleaning was done using Epi Info version 3.5.3 computer software. Descriptive statistics of SPSS version 20 was used to summarize all the values of the variables. Pearson's $x^{2}$ test and binary logistic regression with $95 \% \mathrm{CI}$ were computed as measures of association. To assess the association between the different predictor variables of diarrheal occurrence in under-five children with the dependent variables, first binary relationships between each independent variable and outcomes were investigated using a binary logistic regression model. All variables with $P$ value less than 0.2 were included in the multiple logistic regression models, and $\mathrm{P}$ value of less than 0.05 was considered as statistically significant.

2.10. Ethical Approval. Ethical clearance was obtained from the Ethical Committee of the University of Gondar. Permission and support letter was obtained from North Gondar Zone Health Bureaus. The purpose and importance of the study was explained to each study participant. To ensure confidentiality of participants' information, anonymous typing was applied whereby the name of the participant and any identifier of participants were not written on the questionnaire, and to keep the privacy during the interview, they were interviewed alone. Above all data was collected after full verbal consent was obtained from study participants. Children who have diarrhea during the interview were treated using ORS and zinc tablets and then sent to nearby hospital.

\section{Results}

3.1. Sociodemographic Characteristics and Occurrence of Diarrheal Disease. A total of 736 under-five children and their mothers with 99\% (736/743) response rate from different rural areas of North Gondar Zone (Dembia, Gondar Zuria, Chilga, and Sanja) were enrolled during the study. Of these more than half, $55.7 \%$ (410/736), were males. Majority of mothers were in the age group of 25-34 years with mean age of $30.7 \%$. Almost all respondents were biological mothers 96.4\% (709/736), married 94.2\% (693/736), and house wives $86 \%(632 / 736)$. The educational status of mothers/guardians showed that $58 \%(431 / 736)$ of them were unable to read and write, while only $4.5 \%$ of them attended high school and above. The overall prevalence of diarrheal disease among under-five children was $22.1 \%$ (163/736). Of these, children with age group of less than one year old, $7.7 \%$ (57/736), were commonly infected with diarrheal diseases; moreover, children who practice partial breast feeding were more infected with diarrheal disease, 15.5 (114/736), while $2.5 \%(18 / 736)$ of them who practice exclusive breastfeeding were less infected with diarrheal diseases. Households with family size of less than five were reported to be highly exposed to diarrheal diseases, $14.3 \%$ (105/736) (Table 1).

3.2. Factors Associated with Diarrheal Diseases among UnderFive Children. Bivariate and multivariate analysis on socioeconomic variables, like the age, district hygiene and sanitary condition, educational status of father, and current breast feeding, are shown in Table 2. The occurrence of diarrheal disease was associated with the number and age of underfive children in the households. The occurrence of diarrhea was 1.82 times more likely to be higher among households with less than or equal to one-year children compared with households with four- to five-year children $[\mathrm{AOR}=3.89,95 \%$ $\mathrm{CI}=(1.58,9.57)]$. The occurrence of diarrhea was significantly associated with district hygiene and sanitary condition. In relation to hygiene and sanitary condition, the probability of diarrheal occurrence among under-five children was 3 times higher in Dembia district compared to Sanja district. Childhood diarrheal disease was statistically associated with the educational status of mothers/caretakers. The likelihood 
TABLE 2: Bivariate and multivariate analysis of sociodemographic factors related to diarrhea among under-five children in rural areas of North Gondar Zone, Northwest Ethiopia, 2016.

\begin{tabular}{|c|c|c|c|c|}
\hline \multirow[t]{2}{*}{ Variables } & \multicolumn{2}{|c|}{ Diarrhea $(N=736)$} & \multirow[t]{2}{*}{ COR $(95 \% \mathrm{CI})$} & \multirow[t]{2}{*}{$\operatorname{AOR}(95 \% \mathrm{CI})$} \\
\hline & Yes $(\%)$ & No (\%) & & \\
\hline \multicolumn{5}{|l|}{ Age group of index child } \\
\hline 0-1 year & $57(7.7)$ & $134(18.2)$ & $3.899(1.589-9.570) *$ & $1.824(1.396-4.163) *$ \\
\hline $1-2$ years & $47(6.4)$ & $127(17.3)$ & $3.392(1.370-8.400) *$ & $1.473(0.484-4.486)$ \\
\hline $2-3$ years & $38(5.2)$ & $138(18.8)$ & $2.524(1.010-6.308) *$ & $1.458(0.518-4.103)$ \\
\hline 3-4 years & $15(2.0)$ & $119(16.2)$ & $1.155(0.425-3.138)$ & $0.681(0.222-2.085)$ \\
\hline $4-5$ years & $06(0.8)$ & $55(7.5)$ & 1 & 1 \\
\hline \multicolumn{5}{|c|}{ District hygiene and sanitary condition } \\
\hline Dembia & $64(8.7)$ & $96(13.0)$ & $2.341(1.464-3.744) * *$ & $3.035(1.674-5.504) *$ \\
\hline Gondar Zuria & $36(4.8)$ & $175(23.8)$ & $0.723(0.439-1.190)$ & $1.150(0.636-2.081)$ \\
\hline Chilga & $22(3.0)$ & $158(21.5)$ & $0.489(0.278-0.860) *$ & $0.822(0.394-1.714)$ \\
\hline Sanja & $41(5.6)$ & $144(19.6)$ & 1 & 1 \\
\hline \multicolumn{5}{|c|}{ Relation of the respondent to the child } \\
\hline Mother & $155(21.1)$ & $554(75.3)$ & 1 & 1 \\
\hline Father & $05(6.8)$ & $16(2.2)$ & $1.117(0.403-3.097)$ & $1.949(0.639-5.948)$ \\
\hline Caretaker & $03(0.4)$ & $03(0.4)$ & $3.574(0.714-17.884)$ & $6.125(0.955-9.267)$ \\
\hline \multicolumn{5}{|c|}{ Age group of mother/guardian } \\
\hline $15-24$ years & $36(4.9)$ & $115(15.6)$ & $1.574(0.941-2.632)$ & $1.166(0.578-2.355)$ \\
\hline 25-34 years & $90(12.2)$ & $272(37.0)$ & $1.663(1.087-2.546) *$ & $1.577(0.950-2.620)$ \\
\hline$>35$ years & $37(5.0)$ & $186(25.3)$ & 1 & 1 \\
\hline \multicolumn{5}{|l|}{ Religion of parents } \\
\hline Orthodox & $159(21.6)$ & $531(72.2)$ & $3.693(1.124-12.137) *$ & $1.873(0.516-6.796)$ \\
\hline Protestant & $01(0.1)$ & $05(0.7)$ & $2.467(0.213-28.535)$ & $1.096(0.084-14.386)$ \\
\hline Muslim & $03(0.4)$ & $37(5)$ & 1 & 1 \\
\hline \multicolumn{5}{|c|}{ Educational status of mother/guardian } \\
\hline Unable to read and write & $85(11.6)$ & $346(47)$ & $4.076(1.933-8.592) * *$ & $4.373(1.725-11.085) *$ \\
\hline Read and write & $18(2.5)$ & $44(6.0)$ & $1.713(1.056-2.777) *$ & $1.778(1.024-3.089) *$ \\
\hline Grade $1-8$ & $34(4.6)$ & $101(13.7)$ & $1.408(0.871-2.276)$ & $2.110(1.128-3.947) *$ \\
\hline Grade 9-12 & $10(1.4)$ & $65(8.8)$ & $1.301(0.739-2.292)$ & $2.377(1.021-5.535) *$ \\
\hline Greater than grade 12 & $16(2.2)$ & $17(2.3)$ & 1 & 1 \\
\hline \multicolumn{5}{|c|}{ Educational status of father } \\
\hline Unable to read and write & $63(8.6)$ & $291(39.5)$ & $3.831(1.860-7.892) * *$ & $2.136(0.810-5.638)$ \\
\hline Read and write & $33(4.5)$ & $89(12.1)$ & $1.665(0.916-3.027)$ & $1.085(0.537-2.192)$ \\
\hline Grade $1-8$ & $32(4.4)$ & $105(14.3)$ & $1.370(0.869-2.161)$ & $1.131(0.609-2.102)$ \\
\hline Grade 9-12 & $20(2.7)$ & $71(9.6)$ & $0.626(0.309-1.270)$ & $0.392(0.154-1.001)$ \\
\hline Greater than grade 12 & $15(2.0)$ & $17(2.3)$ & 1 & 1 \\
\hline \multicolumn{5}{|c|}{ Current breastfeeding status } \\
\hline Exclusive breastfeeding & $18(2.5)$ & $56(7.6)$ & 1 & 1 \\
\hline Partial breastfeeding & $114(15.5)$ & $255(34.6)$ & $2.717(1.420-5.196) *$ & $1.981(0.717-5.476)$ \\
\hline Not breast feeding & $31(4.2)$ & $262(35.6)$ & $3.778(2.451-5.825) * *$ & $3.128(1.622-6.033) * *$ \\
\hline \multicolumn{5}{|l|}{ Measles vaccination status } \\
\hline Yes & $120(16.3)$ & $470(63.9)$ & 1 & 1 \\
\hline No & $43(5.8)$ & $103(14.0)$ & $1.635(1.087-2.460) *$ & $1.190(0.615-2.303)$ \\
\hline
\end{tabular}

* Significant association at $\mathrm{p}<0.05, * *$ Significant association at $\mathrm{p}<0.001,{ }^{1}$ Occurrence of child diarrhea.

of diarrheal occurrence was 4.37 times higher among children whose mothers/guardians had unable to read compared with educational status of grade $>12$ and above $[\mathrm{AOR}=4.37,95 \%$ $\mathrm{CI}=(1.73,11.1)]$.
Moreover, current breast feeding practice was significantly associated with occurrence of diarrheal disease. The risk of developing diarrhea was 3.13 times higher among children whose mothers had no breast feeding practice 
$[\mathrm{AOR}=3.13,95 \% \mathrm{CI}=(1.62,6.03)]$ compared to children whose mothers had exclusive feeding.

\section{Discussion}

This study investigated the prevalence of diarrheal occurrence and sociodemographic characteristics among underfive children in rural areas of North Gondar Zone. The overall prevalence of diarrhea in this study was $22.1 \%$; this was in line with the study conducted in eastern Ethiopia, $22.5 \%[13,14]$, and Somalia region. However, it was lower than those reported in the studies conducted in Burundi rural areas, 32.6\% [15]; nomadic population in Afar region, 26.1\% [16]; Arba Minch, Southern Nationalities, and Peoples' region, 30.5\% [17]; and Jijiga, Somalia region 27.3\%[14]. This might be due to the inclusion of only rural children and the difference in provision health service between rural and urban population. However the current finding was higher than the finding of the Ethiopian demographic and health survey 2016 (EDHS), in which the magnitude of diarrheal disease among children younger than 5 years old was $12 \%$ [18], study conducted in West Gojjam, 18\% [19], and North Gondar Zone, Amhara region 15\% [20]. The possible explanation for this difference could be the variation in the sociodemographic characteristics of the study subjects, socioeconomic development, and study periods. People's living style, behavioral change, and communication strategies of these areas could also contribute notably to such variations.

The children aged 0-1 year old were at high risk of developing diarrhea compared to children aged $\mathrm{b} / \mathrm{n} 4-5$ years old. This findings was in line with studies conducted in Arba Minch, southern Ethiopia [17], India [21], Sudan [22], and Thailand [23]. The high prevalence of diarrhea at this age could be due to the low immunity of children, introduction of contaminated weaning foods, and crawling starting at this age and the risk of ingesting contaminated foods and drinks.

The present study found that the odds of diarrheal diseases of children whose mothers/caretakers cannot read and write were higher than those of children whose mothers/guardians had grade greater than 12 and above level of education. This is also similar to previous studies conducted in Jijiga, Somalia region [14]; Hadaleala district, Afar region, northeast Ethiopia [16]; Arba Minch, southern Ethiopia [17]; and Sheko district, southwest Ethiopia [24]. This may be due to the fact that education is likely to enhance household health and sanitation practices. Education can increase awareness about the transmission and prevention methods of diarrhea. It also encourages changes in behavior at the household level.

Findings of our study showed that diarrheal occurrence was associated with children that do not have breast feeding in their early age. This was also agreed with other reports from Gojjam, west Ethiopia, indicating that not breastfeeding resulted in an excess risk of diarrhea mortality in comparison to exclusive breastfeeding among infants aged 0-5 months and to any breastfeeding among children aged 6-23 months $[25,26]$.

\section{Conclusion}

The study revealed that childhood diarrhea remains an important health concern in the study area. The highest rate of the occurrence of diarrhea was significantly seen among children aged 0-1 year old. Occurrence of diarrhea was statistically associated with child age of less than or equal to one, educational status of mother/guardians and breast feeding. To minimize the magnitude childhood diarrhea, various designing and implementing strategies, such as health education, child care, early vaccination of children, and weaning practice, integrated with the existing national health extension are quite essential.

5.1. Limitation of the Study. Maternal/guardians diarrheal history was not collected.

\section{Abbreviations \\ AOR: Adjusted odds ratio \\ COR: Crude odds ratio \\ $\mathrm{Cl}$ : Confidence interval \\ ETB: Ethiopian birr \\ $\mathrm{N}$ : Number \\ PPS: Probability proportion to size \\ WHO: World Health Organization.}

\section{Data Availability}

Data were collected from each rural area of households having under-five children from North Gondar Administrative Zone, northwest Ethiopia, registered on Microsoft Excel spreadsheet, and entered to SPSS version 20, and all data generated or analyzed during this study are included in this manuscript.

\section{Conflicts of Interest}

The authors declare that they have no conflicts of interest.

\section{Authors' Contributions}

Atalay Getachew participated in the conception and design of the study, data collection and analysis, interpretation of the findings, and drafting and writing the manuscript. Teklay Gebrecherkos participated in the design of the study, data collection, analysis and interpretations of the findings, and final writing of the manuscript. Alebachew Tadie participated in the design of the study, data collection, and analysis and interpretations of the findings. Zemichael Gizaw participated in the design of the study as well as analysis and interpretations of the findings. Mulat Gebrehiwot participated in the design of the study. Daniel Haile Cherkos participated in the design of the study, data collection, and interpretations of the findings. Martha Alemayehu Menberu participated in analysis and interpretations of the findings as well as drafting and final writing of the manuscript. 


\section{Acknowledgments}

The research was funded by the University of Gondar. The authors would like to thank University of Gondar, College of Medicine and Health Sciences, Department of Environmental and Occupational Health and Safety, for allowing them to work on this important public health issue. They wish also to express their profound gratitude to data collectors and personnel of the department, who reviewed the paper and suggested valuable comments.

\section{References}

[1] M. Kahlown, M. Tahir, H. Rasheed, and K. Bhatti, "National water quality monitoring programme," Tech. Rep. Fourth Technical Report, Pakistan Council of Research in water Resources, 2006.

[2] M. Kosek, C. Bern, and R. L. Guerrant, “The global burden of diarrhoeal disease, as estimated from studies published between 1992 and 2000," Bulletin of the World Health Organization, vol. 81, no. 3, pp. 197-204, 2003.

[3] C. Boschi-Pinto, L. Velebit, and K. Shibuya, "Estimating child mortality due to diarrhoea in developing countries," Bulletin of the World Health Organization, vol. 86, no. 9, pp. 710-717, 2008.

[4] U. D. Parashar, J. S. Bresee, and R. I. Glass, "The global burden of diarrhoeal disease in children," Bulletin of the World Health Organization, vol. 81, no. 4, 2003.

[5] World Health Organization, Guidelines for Safe Recreational Water Environments: Coastal And Fresh Waters, World Health Organization, 2003.

[6] B. Mengistie, Y. Berhane, and A. Worku, "Prevalence of diarrhea and associated risk factors among children under-five years of age in Eastern Ethiopia: A cross-sectional study," Open Journal of Preventive Medicine, vol. 03, no. 07, pp. 446-453, 2013.

[7] A. Mamo and A. Hailu, "Assessment of prevalence and related factors of diarrheal diseases among under-five year's children in debrebirehan referral hospital, debrebirehan town, North Shoa Zone, Amhara Region, Ethiopia," Open Access Library Journal, vol. 01, no. 01, pp. 1-14, 2014.

[8] S. Karambu, V. Matiru, M. Kiptoo, and J. Oundo, "Characterization and factors associated with diarrhoeal diseases caused by enteric bacterial pathogens among children aged five years and below attending Igembe District Hospital, Kenya," The Pan African Medical Journal, vol. 16, no. 1, 2013.

[9] J. B. Richards, "Drinking Water monitoring and surveillance," African health, vol. 4, no. 10, 1996.

[10] G. Howard and K. Pond, Drinking Water Surveillance Programs in The South East Asia Region. Updated Situation Assessment And Recommendation for Future Activity, WHO, Regional Office for South-East Asia, New Delhi, India, 2002.

[11] P. R. Battu and M. S. Reddy, "Bacteriological examination of drinking water with reference to coliforms in Jeedimetla, Hyderabad, India," African Journal of Biotechnology, vol. 8, no. 20, pp. 5495-5496, 2009.

[12] G. Mitike, "Prevalence of acute and persistent diarrhoea in North Gondar zone, Ethiopia," East African Medical Journal, vol. 78, no. 8, pp. 433-437, 2000.

[13] M. Kaba and F. Ayele, "Ethnographic study of diarrhoeal diseases among under-five children in Mana District, Jimma Zone, Southwest Ethiopia," Ethiopian Journal of Health Development, vol. 14 , no. 1,2000 .
[14] A. Hashi, A. Kumie, and J. Gasana, "Prevalence of Diarrhoea and Associated Factors among Under-Five Children in Jigjiga District, Somali Region, Eastern Ethiopia," Open Journal of Preventive Medicine, vol. 06, no. 10, pp. 233-246, 2016.

[15] K. Diouf, P. Tabatabai, J. Rudolph, and M. Marx, "Diarrhoea prevalence in children under five years of age in rural Burundi: An assessment of social and behavioural factors at the household level," Global Health Action, vol. 7, no. 1, Article ID 24895, 2014.

[16] W. Woldu, B. D. Bitew, and Z. Gizaw, "Socioeconomic factors associated with diarrheal diseases among under-five children of the nomadic population in northeast Ethiopia," Tropical Medicine and Health, vol. 44, no. 1, article no. 40, 2016.

[17] S. Mohammed and D. Tamiru, "The Burden of Diarrheal Diseases among Children under Five Years of Age in Arba Minch District, Southern Ethiopia, and Associated Risk Factors: A Cross-Sectional Study," International Scholarly Research Notices, vol. 2014, pp. 1-6, 2014.

[18] Central Statistical Agency (CSA), "Ethiopia demographic and health survey," Addis Ababa, Ethiopia, and Rockville, Maryland, USA, 2016.

[19] M. Dessalegn, A. Kumie, and W. Tefera, "Predictors of underfive childhood diarrhea: Mecha district, West Gojam, Ethiopia," Ethiopian Journal of Health Development, vol. 25, no. 3, pp. 192 200, 2012.

[20] R. P. Mediratta, A. Feleke, L. H. Moulton, S. Yifru, and R. Bradley Sack, "Risk factors and case management of acute diarrhoea in North Gondar Zone, Ethiopia," Journal of Health, Population and Nutrition, vol. 28, no. 3, pp. 253-263, 2010.

[21] S. S. Avachat, V. D. Phalke, D. B. Phalke, S. M. M. Aarif, and P. Kalakoti, "A cross-sectional study of socio-demographic determinants of recurrent diarrhoea among children under five of rural area of western Maharashtra, India," Australasian Medical Journal, vol. 4, no. 2, pp. 72-75, 2011.

[22] S. Siziya, A. S. Muula, and E. Rudatsikira, "Correlates of diarrhoea among children below the age of 5 years in Sudan," African Health Sciences, vol. 13, no. 2, pp. 376-383, 2013.

[23] C. Wilunda and A. Panza, "Factors associated with diarrhea among children less than 5 years old in Thailand: a secondary analysis of Thailand multiple indicator cluster survey," Journal of Health Research, vol. 23, pp. 17-22, 2009.

[24] T. Gebru, M. Taha, and W. Kassahun, "Risk factors of diarrhoeal disease in under-five children among health extension model and non-model families in Sheko district rural community, Southwest Ethiopia: Comparative cross-sectional study," BMC Public Health, vol. 14, no. 1, article 395, 2014.

[25] L. M. Lamberti, C. L. F. Walker, A. Noiman, C. Victora, and R. E. Black, "Breastfeeding and the risk for diarrhea morbidity and mortality," BMC Public Health, vol. 11, supplement 3, article S15, 2011.

[26] Z. A. Anteneh, K. Andargie, and M. Tarekegn, "Prevalence and determinants of acute diarrhea among children younger than five years old in Jabithennan District, Northwest Ethiopia, 2014," BMC Public Health, vol. 17, no. 1, pp. 1-8, 2017. 


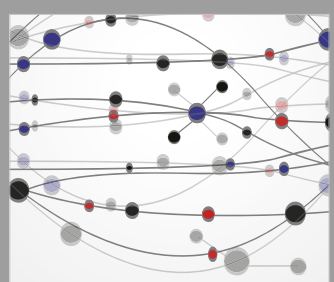

The Scientific World Journal
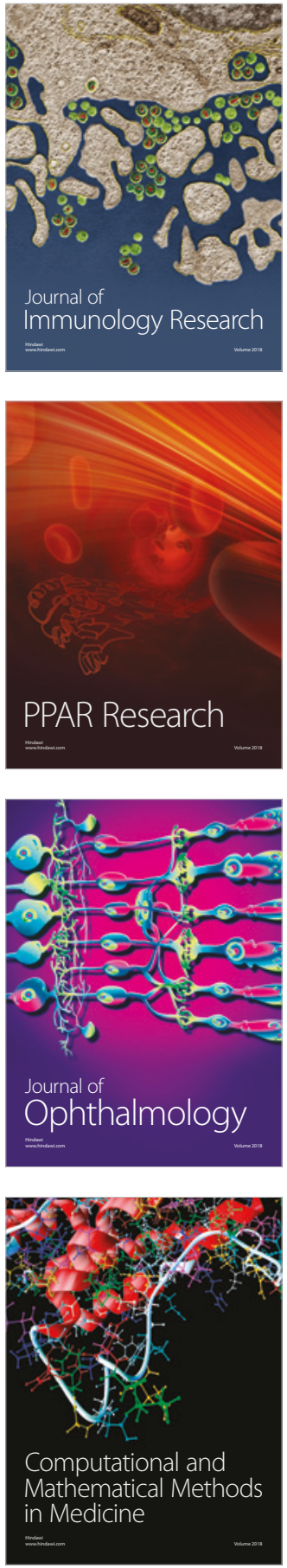

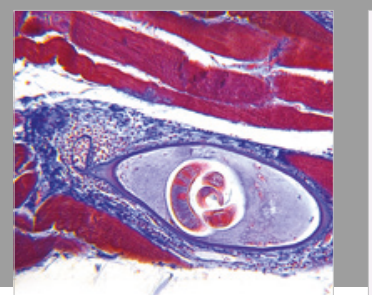

Gastroenterology Research and Practice

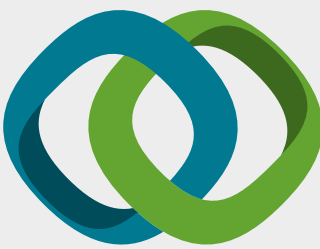

\section{Hindawi}

Submit your manuscripts at

www.hindawi.com
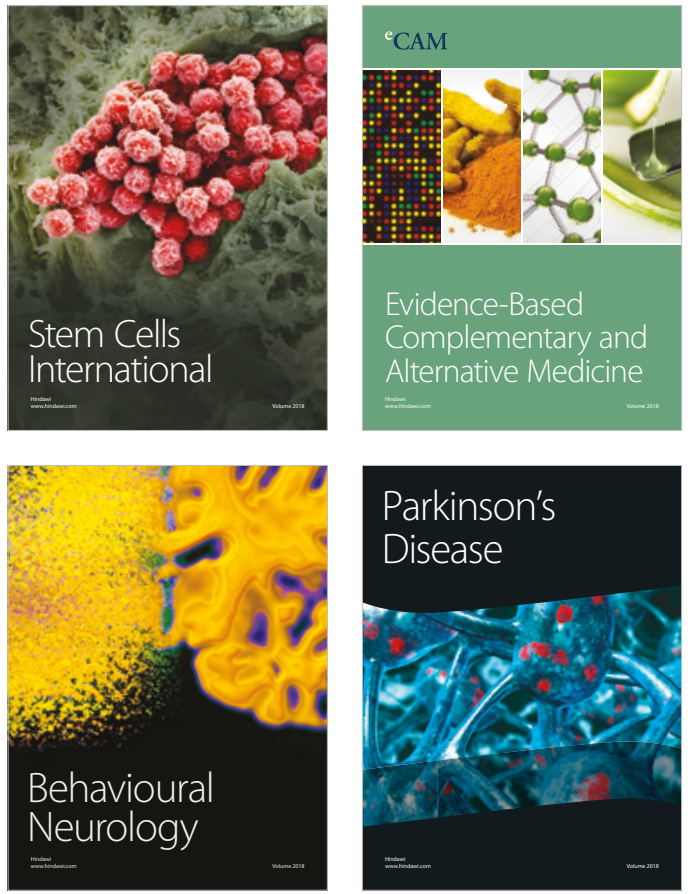

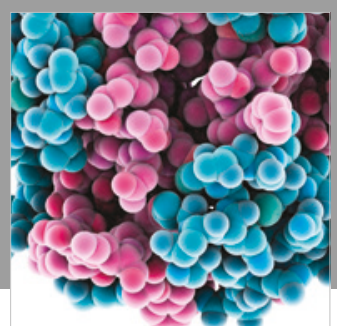

ournal of

Diabetes Research

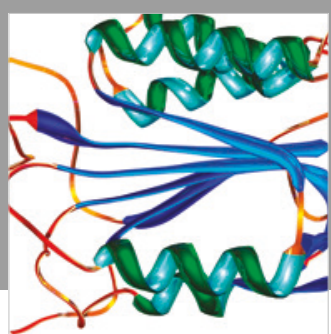

Disease Markers
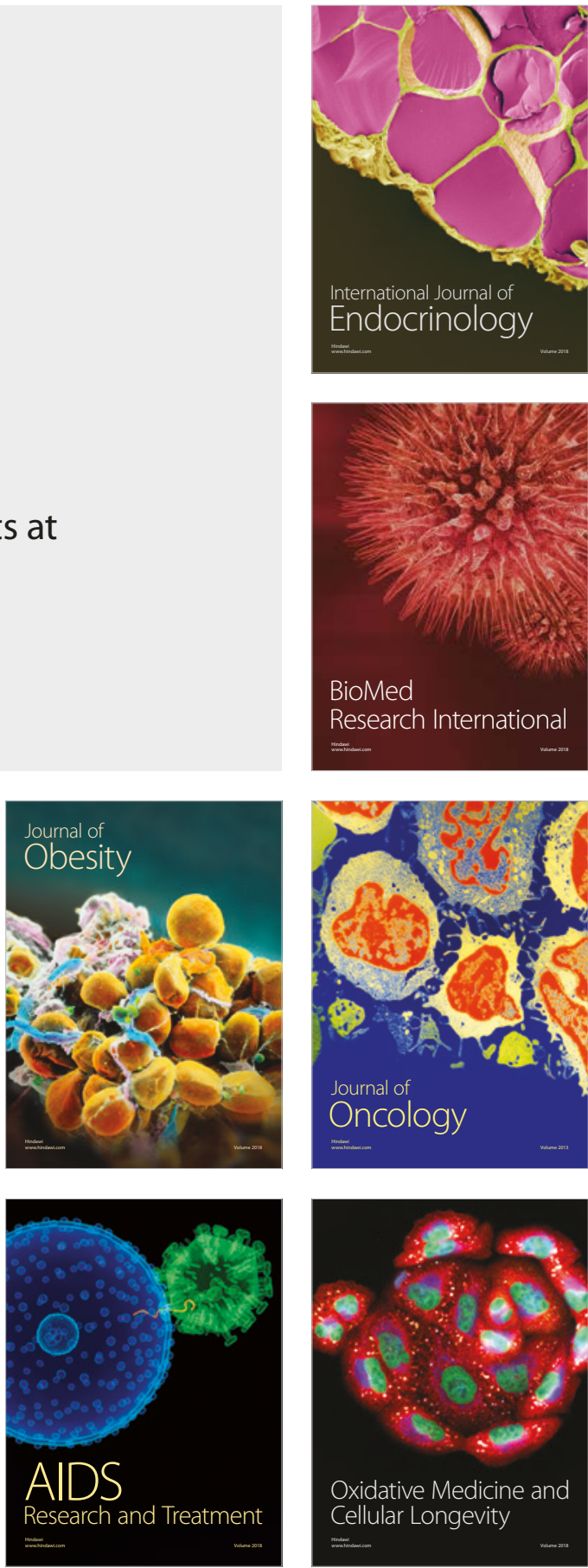